\title{
Identity politics and national integration in Nigeria
}

\author{
Emmanuel Ikechi Wonah
}

University of Port Harcourt, Port Harcourt, Nigeria

\section{OPEN ACCESS}

Citation: Wonah E. I. (2016) Identity politics and national integration in Nigeria. Open Science Journal 1(3)

Received: $13^{\text {th }}$ May 2016

Accepted: $20^{\text {st }}$ June 2016

Published: $7^{\text {th }}$ March 2017

Copyright: (C) 2016 This is an open access article under the terms of the Creative Commons Attribution License, which permits unrestricted use, distribution, and reproduction in any medium, provided the original author and source are credited.

Funding: The author(s) received no specific funding for this work

Competing Interests: The author has declared that no competing interests exist.
${ }^{*}$ Corresponding author: Emmanuel Ikechi Wonah: emmagreat4luv@yahoo.com

\begin{abstract}
:
The aim of the paper is to examine the impact of identity politics on national integration in Nigeria. This paper relies on secondary sources of data, and contends that identity politics can create the necessary awareness and actions needed to redress the inequities promoted by the structural imbalance of the Nigerian State. The redress of the inequities can be a stabilizing force necessary for the actualization of national integration in Nigeria. On the other hand, it argues that identity politics can also be a divisive factor which can seriously threaten the corporate existence of Nigeria and make our quest for integration illusory. Also, the paper is of the view that national integration can be achieved when identity politics is guided by certain objective conditions expressed in democracy. Therefore, it recommends that there should be an internalization and demonstration of the democratic culture in everyday life of Nigerians.
\end{abstract}

Keywords: Identity Politics, National Integration, Stabilizing Force, Democracy, Structural Imbalance.

\section{Introduction}

The gregarious nature of a man is consummated by the inadequacies nature places on him. Thus, a man loves living in a community with his fellow men for self and collective actualization. However, this communal life is threatened by the ever-conflicting interest of men which can be resolved by institutionalized means 
of social justice, equity, tolerance, and equality especially in terms of participation in the decision-making process. These institutionalized means can contribute immensely in stabilizing the political system, thereby engendering the cohesion of the various competing groups in a society.

In order to achieve such cohesion within the purview of group dynamics, the various competing groups must be given a sense of belonging in the scheme of things. Basically, it is the need to protect the interest of these groups that in most cases reinforces such identities as ethnic groups, religious affiliations, racial, and gender cleavages.

As a plural society, Nigeria is made up of different ethnic and religious groups which compete not only for resources within the political landscape but also for the assertion of their various identities. The effect is that it tends to plunge the country into seemingly intractable political imbroglio which threatens the corporate existence of the various groups and their quest for national integration. It is against this back-drop that this paper examines the centripetal and centrifugal forces of identity politics which can tremendously influence the actualization of national integration in Nigeria.

\section{Theoretical framework}

This study adopts the group theory as the basis of the analysis. The group theory primarily deals with groups rather than individuals as the major component of the political system. It emphasizes the fact that the society is made up of different groups which are not just a collection of individuals but a web of interactions. Different groups, according to David Truman, are based on the notion of interest. (Truman cited in Ray 2003: 19). The shared attitudes constitute the interest. Every group is basically an interest group.

Therefore, it becomes evident that the taproot of every group is the interest of the members it protects. In the course of protecting their interest, the groups assert their identities and strategize on how best to have access to state resources. Oftentimes, these interests clash and if there is no adequate institutional arrangement hoisted on democratic values, it can degenerate to conflict. Identity politics is seen as the conscious efforts made by a group in relation with other groups to protect its interest and assert its identity. Thus, within the purview of group dynamics, the reality of politics is hidden below the surface of the properly constituted and recognized organs through which decisions are articulated. It is hidden in the continuous struggle for power and influence upon which groups are constantly engaged (Ray 2003:19). Consequently, the struggle for power, influence, and the protection of different groups' interests makes the political system volatile and more susceptible to conflict.

The relevance of the group theory in this paper can be seen from the fact that Nigeria is a plural society. It is made up of different ethnic groups that are constantly struggling for power, influence, and the protection of their interests. This struggle became more devastating given the fissiparous (divisive) tendencies inherent in the colonial policies of indirect rule and isolation. The sudden amalgamation of the different ethnic groups in 1914 became a 'marriage of 
inconvenience', which heightened the fear of domination and suppression among the groups.

In the light of this fear, the different ethnic groups shrank into their 'ethnic cocoons' in a bid to protect their interest and assert their identities. This was demonstrated by the ethnic formation of political parties. Thus, rather than playing the traditional role of interest aggregation for national integration, political parties by virtue of their formation and intents, became agents of disunity.

From another perspective, the State and its apparatuses in Nigeria are seen as means of protecting selfish and sectional interests. The political elites formulate policies and make laws that deny people a sense of belonging. For example the Petroleum Decree No. 51 of 1969, was a reaffirmation of the exploitative colonial administration's "minerals ordinance" of 1949. Subsection 2 section 1 of the decree states that:

All land (including land covered by water), which is in Nigeria or under the territorial waters of Nigeria, which forms part of the continental shelf, shall be vested in the State (Dodo 2005).

Another example is the Petroleum Production and Distribution (Antisabotage) Decree 1975. This Decree, among others, makes it an offence punishable by death by a firing squad or twenty-one years imprisonment for anybody with intent to:

Obstruct or prevent the production or distribution of petroleum product in any part of Nigeria or willfully do anything with intent to obstruct or prevent the procurement of petroleum products for distribution in any part of Nigeria, willfully does anything in respect of any vehicle or public high way with intent to obstruct or prevent the use of the vehicle or public highway for the distribution of petroleum product (Dodo 2005).

Prevention of oil prospecting companies or their tools from mobilizing to site constituted sabotage and those caught in the act were to be tried by military tribunals, not subject to any laws or court in Nigeria (Dode, 2005: 123). This decree adds to the hardship faced by the people of Niger Delta. For instance, it denies them of their right to fair-hearing and relegates the judiciary to the background. Another obnoxious decree is the land use decree which transfers the ownership of all land within Nigeria's territory to the State.

These decrees, among others, were conscious efforts made by the Nigerian State to control the exploration, exploitation, distribution, marketing of oil, and the proceeds at the expense of the Niger Delta people. Thus, the brazen exploration and exploitation of oil in the Nigeria's Delta region without regard to the welfare promotion and the protection of the environment is not only a daylight robbery but also a calculated attempt to make people strangers in their own land and eventually exterminate them from the surface of the Earth.

The violent confrontation of the Oil Companies and the federal government (when dialogue failed) by the youth of Niger Delta was matched with brute force. The mobilization of the coercive apparatuses of the State against the people of Odi in Bayelsa State, the Umuechem massacre in Rivers State, the hanging of Ken Saro-Wiwa and his OgoniKinsmen in what looked like a melodrama, the 
near-death trap condition of the environment and poverty in Niger Delta, among other things, prove the fact that the Nigerian State is not sincerely committed to national integration.

It should be noted that the few decrees mentioned in this paper are the products of the military rule in Nigeria. Also, noteworthy is the fact that the rank and file of the military is dominated by the three major ethnic groups Hausa-Fulani, Yoruba, and Igbo. We are tempted to believe that if the oil had been found in Sokoto, Zamfara, Abeokuta, Oshogbo, Enugu, or Nnewi, these decrees would not have been promulgated. After all, nothing has been done, not even a decree had been promulgated to centralize the production, distribution, marketing, and sharing of the proceeds from agricultural products that were controlled by the three major ethnic groups.

Moreover, the domination of Oil Companies in Nigeria, Federal Institutions, and some agencies especially at the management level, by some ethnic groups explains a part of the structural imbalances that characterize the Nigerian State. Another fact is the militarization of the State and the Nigeria's populace as a result of many years of military interregnum coupled with the insensitivity of the State to the plight of the people seems to make might to be right in the minds of Nigerians. Thus, it appears the only language the Nigerian State and her people understand is violence. The militancy in the Niger Delta and the insurrection of the Boko Haram sect testify that.

The above instances have been given in order to show that the activities of a group in relation to the activity of other groups in a plural society go a long way in understanding the dynamics of a political system, especially as it concerns its efforts towards achieving national integration. It is also obvious that the State plays a harmonizing role in the quest for national integration.

\section{Conceptual clarification - Identity politics}

The notion of identity politics derives from the combination of two words, identity and politics. Identity means the state or quality of being identical, or the same. It follows that a group of persons may have certain traits, features, cultural realities, economic status etc. that bind them together. These markers distinguish a group from other groups and place that group on a different pedestal depending on how it asserts its identity in its relationship with other groups. The assertion of the group's identity may not be a wishful thinking, it finds expression within the context of the group's identifiable interest and it is concretized and actualized by not only the availability of resources at the group's disposal, but also the effective and efficient mechanism of resource distribution.

On the other hand, politics is the allocation of resources through institutionalized means for the harmonization and protection of the various interests in a social formation. Thus, each group strives for the available resources in order to protect its interests and assert its identity. The social formation is characterized by competition among the various groups which, when not properly and fairly regulated, can destabilize the political system and threaten the corporate existence of the various interest groups. Therefore, identity politics refers to the conscious efforts made by a group to protect its 
interest and assert its identity. It also means that political arguments that focus upon the self-interest and the perspectives of social minorities or self-identified social interest groups and the way in which people's politics are shaped by certain aspects of their identity such as race, class, religion, sexual orientation, or traditional dominance.

It appears to be more glaring that a group tends to assert its identity when in most cases there is an oppressive mechanism usually in the form of a political structure designed to oppress, subjugate, exploit, and relegate it to the background. This view was succinctly captured by (Young 1990), when he said that identity politics, as a mode of organizing, is intimately connected to the idea that some social groups are oppressed. Consequently, it can be seen as the politics of group based movement claiming to request the interests and identity of a particular group, rather than policy issues relating to all members of the community.

In most cases, identity politics can be deceptive. This is because instead of being seen as the politics of recognition since it demands recognition on the basis of the very grounds on which recognition has previously been derived, most leaders of certaingroups hide under the guise of identity politics to exploit and marginalize members of their own group for their selfish interests. Unfortunately, this makes the group more susceptible to exploitation, oppression, and marginalization by other groups. Given this circumstance, the group becomes entangled in what may be referred to as victim politics - a situation where a group identifies itself as oppressed and seek either to end that oppression, or to use that oppression to justify their actions in other spheres. Thus, they constantly struggle to extricate themselves from the clutches of supremacist politics - a situation where groups seek to dominate other groups for what they see as the "legitimate" reason (Watts 2008:22-23).

The emergence of modern concerns with ethnicity and social movement led to anthropological postulations about identity. Notable in this regard is the Eriksonian understanding of identity which focused on the uniqueness of individuality which makes a person distinct from others. It refers to the qualities of sameness in relation to a person's direction to others and to a particular group of people. This view was reinforced by the trend in sociological thought which explains the manner in which the individual is affected by and contributes to the overall social context. The above view according to (Young, 1990) led to the crystallization of two approaches of interpreting the concept of identity. The first is known as essentialism, also referred to as primordial approach, which holds that identification with a particular group is a natural and fixed thing, defined by objective criteria such as common ancestry and common biological characteristics e.g. sexuality. Whereas, the second is the social constructionist theory which holdsthe positionthat identity is formed by a predominantly political choice of certain characteristics. Therefore, it questions the idea that identity is a natural thing characterized by fixed, supposedly objective criteria (Young, 1990). Granted that people with different backgrounds can join an interest group to protect their own interest, it is also evident that people with the same physical or biological features gravitate around avowed interests which pull them together. Thus, it is not necessarily because one is a black man that one joins a movement for black nationalism,more importantly is the consideration of the interest of the blacks vis-à-vis other races. The moment the interest fritters away such 
categorization or movement becomes superfluous. For instance, how can one explain the situation in the Niger Delta region of Nigeria where the over celebrated case of marginalization, oppression, and exploitation of the people has given rise to a plethora of movements or groups claiming to represent the interest of the people of Niger Delta when it is obvious that these movements/groups lack the norms of univocality as they sing with discordant tunes. Most of these movements sometimes inflict harm on their people as a result of their struggle for supremacy. They also kidnap their own people for ransom all in the name of resource control. Again, due to their overbearing influence, they bunker oil and use the proceeds for ostentatious consumption while a good number of people are still wallowing in a seemingly abysmal poverty and underdevelopment. Worse is the fact that a part of the political elite diverts the revenue meant for the development of the area into private pockets and also squander the revenue in frivolous projects and programs which have no direct bearing on people's lives.

Another reference point is the feudal tango in the Hausa-Fulani axis of Northern Nigeria where some indigenes of the area are subjected to life of servitude and perpetual dependency. The above instances and other related cases cast doubt in the minds of many people regarding the potency of identity politics in actually protecting the interest of a group and at the same time asserting their identity. Rather, it reinforces the temptation to believe that identity politics is simply deceptive and that it is a game for ethnic chauvinists or religious bigots who hide under the cloak of ethnicity, religious belief, or other forms of identity to protect their selfish and parochial interests. This scenario can be likened to the proverb stating that the "dog has chewed the bone that is hung on its neck". Also, there is a temptation to believe that identity politics has the "voice of Jacob and at the same time the hand of Esau"

\section{National integration}

National integration presupposes the fact that the political unit is pluralized since different component units compete for resources in other to protect their interest and assert their identities. This diversity, especially since it is expressed in the ethnic configuration of the society, negates the prospects for national integration. According to (Weiner, 1971 as cited in Ibodje and Dode 2007:121), integration presupposes existence of some elements of pluralism, which may be ethnic, sociocultural, economic, language or political whereby each consciousness can hinder the process of creating a sense of territorial nationality. This could be likened to the biblical Tower of Babel where the builders were inflicted with different languages and as a result they were bereft of understanding, things fell apart and the center could no longer hold.

It may not be correct in all cases that ethnic identity politics protects selfish interest, but it is more glaring that ethnic identity politics have come to stay in Nigerian politics. This is mainly the result of the inequities in terms of power and resource distribution occasioned by the homogenizing effect of the post-colonial State. This was aptly captured by Obi, 2001:14 when he said that, in Nigeria, this homogenizing process has been problematic and is currently being undermined by authoritarianism, socioeconomic crisis, and the inequities 
embedded in the distribution of power in an ethnically plural oil renter context. These pressures have not only contributed to the resurgence of ethnicity, but have laced it with violence and conflict.

In practical terms, the view of Obi, 2001 has been demonstrated by the plethora of ethnic conflicts in Nigeria. For instance, the Ife/Modakeke conflict, the Ijaw/Itsekiri conflict, the Aguleri/ Umuleri conflict, the Eleme/Okrika conflict, the Niger Delta/Nigerian State conflict, the seemingly perennial conflicts in some parts of Plateau State and the unimaginable horror unleashed upon the Nigerian populace by the Boko Haram sect in the guise of religious fanaticism. Behind the glare of these conflicts is the domination, repression, marginalization, and exploitation of one ethnic group by another. The denial of a group to the State resources through what may be considered as politics of exclusion perpetrates these conflicts. The State, through its coercive apparatuses, draconian laws, and arbitrary policies suppresses, dominates and marginalize a group(s) to the extent in which they (the groups) no longer have a sense of belonging in the scheme of things. Again, conflict can be reactivated when a dominating group, confronted with the "wind of change", refuses to let go an existing repressive order that brings other ethnic groups under its overbearing influence and control. Political elites due to their political power and influence mobilize state resources and its coercive apparatuses to fan the embers of discord between two communities or ethnic groups just to satisfy their personal or sectional interests.

It should be noted that these objective conditions which can lead to conflict also reinforce identity politics thatthreatens the corporate existence of the State and hinder national integration.

On the other hand, identity politics can be a stabilizing force in a plural society by creating the much-needed awareness and objective conditions necessary for national integration. National integration presupposes a condition whereby the different ethnic groups understand the strength and weakness of the groups and are prepared to tolerate one another in an atmosphere of "give and take". Therefore, national integration is the ability of the groups to remain committed to the ideals of unity by guaranteeing equal opportunities and assertion of the identities of the various groups.

\section{The way forward}

What follows is that there must be some objective conditions couched in democratic values for us to actualize the quest for national integration. First is that the different ethnic formations must be adequately represented in the decision-making process. However, there is a caveat in this regard. Those who represent the people must be the people who emerged from the crucible of the popular choice of the electorates. Thus, the electoral system must be orchestrated in such a way that people are not denied of their mandates. It is only when people are adequately represented by their leaders who are the products of a democratic electoral system that their interest can be built in the decision-making process.

Second is the fact that the transcendental government must be based on the concept of the rule of law. This will ensure that democratic values such as social 
justice, fair play, equality, tolerance, transparency, and accountability guide governmental activities, especially since it concerns the resource allocation.

Finally, democratic culture must be a part of the life of not only the leaders but the entire strata of the civil society. People must uphold the tenets of democracy and demonstrate the culture of democracy in their everyday life through democratization process (Wonah, 2010; Ifeanacho and Nwagwu, 2009). However, these democratic cultures can succeed in an atmosphere of economic well-being, which means that poverty which creates alienation and socioeconomic insecurity, and which impel people to seek solace in primary group identity including ethnic or religious identity (IDEA 2000:97) must be eradicated, or at least curbed. Furthermore, poverty coupled with low level of literacy and civic awareness prevents people from fully understanding the intricacies of modern government and the real issues involved in it. As a result, they can be hoodwinked relatively easily by self-seeking ethnic demagogues who present ethnicity as a panacea for their economic woes (IDEA 2000).

In other words, to actualize the quest for national integration, the structural imbalances which can be expressed in the unequal composition of state, unfair distribution of state resources, draconian laws etc., must be restructured in order to give the various ethnic groups a sense of belonging on an equal pedestal.

\section{Concluding remarks}

It is evident from the foregoing that identity politics, apart from the fact that it generates the much-needed consciousness in redressing the chasm of sociopolitical and economic differences existing among the various ethnic groups in Nigeria arising from the dysfunctional structural imbalance of the political system, on the other hand, constitutes some internal and external contradictions which militate against the quest for national integration. The internal contradiction manifests itself when ethnic chauvinists appeal to ethnic sentiments only to protect their personal interest, thereby deepening the crises of identity politics. The external contradiction can be seen when the different ethnic groups, conscious of the structural imbalances, shrink into their "ethnic cocoons' by raising ethnic consciousness for the protection of their interest. This obviously places a knife on the 'chord' that binds them together. We must, in the course of our interaction and discharge of our responsibilities show kindness, be fair and considerate to people no matter the ethnic cleavages. Otherwise, the spirit and feeling of oneness would elude us and national integration would continue to be a mirage in Nigeria.

\section{References:}

Dode, R. (2005) "Fiscal Federalism and Social Conflicts in the Niger Delta", Africa Conflict Profile; Journal of the Centre for Ethnic and Conflict Studies (CENTECS), University of Port Harcourt. Vol.1, No. 2, October, 116-127.

Ibodje, S.W. and Dode, R. (2007), "Political Parties, voting Pattern and National Integration in Nigeria", in Elections and the Future of Democracy in Nigeria, A Jega and O. Ibeanu (eds), Nigerian Political Science Association. Nigeria. 
Ifeanacho, M.I. and Nwagu, J. (2009),"Democratization and National Integration in Nigeria", Research Journal of International Studies-Issue 9 January, 2009. Retrieved from www.eurojournals.comJrjis 9 02.pdf

Institute for Democracy and Electoral Assistance (IDEA) (2000), Democracy in Nigeria-Continuing Dialogue(s) for Nation- Building. Capacity Building Series 10, IDEA, Stockholm, Sweden.

Obi, C.I. (2009), The Changing Forms of Identity Politics in Nigeria Under Economic Adjustment: The Case of the Oil Minorities Movement of the Niger Delta. Research Report No. 119. Adebayo Olukoshi (ed)-Nordiska African Institute, Uppsala.

Ray, S.N. (2003),"Modern Comparative Politics Approaches, Methods and Issues", Prentice-Hall of India Private Limited, New Delhi.

Watts, M. (2008) Petro-Insurgency or Criminal Syndicate: Conflict, Violence and Political Disorder in the Niger Delta. Working Paper No. 16 Institute for International Studies, University of Berkeley, USA.

Wonah, E.I. (2010), "Party Ideology, Campaign and Consolidation of Democracy in Nigeria", in Political Communication and Nigerian Democracy; A Book of Reading G.B. Okon and A. Udoudo (eds), Amethyst \& Colleagues Publishers, Port Harcourt, Rivers State, Nigeria.

Young, I.M. (1990),"Justice and the Politics of Difference", Princeton University Press. 